\title{
Do Gender, Poverty Status and Moisture Stress Affect Wheat Yield? Demonstration Results from Sire, Dodota, Ziway Dugda, and Negele Arsi Districts of Ethiopia
}

\author{
Abdi Etafa $^{1^{*}} \quad$ Degefu Kebede $^{2} \quad$ Kisi Wakweya $^{2} \quad$ Ayalneh Tilahun $^{2} \quad$ Abebe Diriba $^{2}$ \\ 1.International Livestock Research Institute, Addis Ababa, Ethiopia \\ 2.Arsi University, BENEFIT-REALISE Project, Asella, Ethiopia
}

\begin{abstract}
Wheat is an important stable crop in Ethiopia, it is produced in both highland and low land or under high moisture and moisture stress areas of Ethiopia. however, farmers lack of knowledge about appropriate and recommended practice is among bottle neck identified in food insecure and moisture stress areas. This demonstration project is initiated in response to finding appropriate, profitable wheat technology and evaluate improved production practice along farmers practice in moisture stress areas of East Shoa, Arsi and West Arsi zones. It used two improved variety along with local variety. Research recommendation on an area of 0.25 for each variety is used. A total of 48 farmers of which $30 \%$ Women and $20 \%$ NPSNP and $80 \%$ famers are used for the experiment. Accordingly, average yield of kingbird is 33.8 quintal while that of Ogolcho is 32.8 quintals. The study result indicates that both men and women either, the poor or non-poor will harvest and achieve better yield if equally technically supported and accessed to technology. Due consideration to appropriate extension advisory service would enhance yield performance of both men and women and poor and non-poor households. It would be great if future, intervention enhanced availability of appropriate technology that addresses women and men interest. Frontline extension and advisory service providers should be considerate of pertinent issues so that both men and women, PSNP and NPSNP would benefit. Further, strengthening stakeholder partnership with research and development partners network and establishing feedback mechanism has of paramount importance. The use of meteorological information would also be important.
\end{abstract}

Keywords: NPSNP ${ }^{57}$, PSNP ${ }^{58}$, demonstration, Gender, poor and non-poor, food insecurity

DOI: $10.7176 / \mathrm{JPID} / 56-04$

Publication date: November $30^{\text {th }} 2020$

\section{Background and Justification}

Ethiopia is the second largest wheat producing country in Africa next to South Africa. Wheat is mainly grown in the central and south eastern highlands during the main (Meher) rainy season (June to September) and harvested in October-November Wheat yields in Ethiopia lagged other major producers in Africa. From 2004 to 2011, the average yield in Ethiopia was 1.68 tons per hectare. This was about 32 and 39 percent below the Kenyan and South African averages, respectively (Tefera, 2013, Niguse et al, 2015). Arsi, Bale, and parts of Shoa are considered the belt growing area. Bread wheat is the major variety of wheat grown in Ethiopia. Around 5-10\% of wheat in Ethiopia is produced in the state farms, the remaining 90-95\% are produced by the small-scale farms (Bezabih et al, 2015; Tefera, 2012). Oromia, Amhara and SNNPR regions produce 59\%, 28\% and $10 \%$ of the country's wheat, production respectively (Tefera, 2013; Niguse et al., 2015). There are potentials of wheat production under moisture stress areas of Ethiopia and farmers still practice the production. The major problem faced is, lack of appropriate technology resulting in subsequent and frequent crop failure.

Different governmental and non-governmental research organizations conducted intensive research and developed several rust resistant wheat varieties but mostly recommended to highland, and areas with adequate moisture despite some varieties for moisture stress areas. However, low moisture/moisture stressed areas lack access (even do not know) to adaptable variety and haphazardly use variety they got but linking farmers access to available appropriate improved variety reduces crop failure, increases yield and creates better opportunity to sustain food security . Further, the wheat consumption trend in Ethiopia is gradually increasing in urban areas due to high population growth (about 2.6 percent a year), migration of people to urban areas, and changes in lifestyles (Tefera, 2013). Consequently, the Production fell short of domestic consumption requirements and the country remained a net importer of wheat. Due to the unbalanced demand and supply, wheat demand has significantly risen in the last couple of years at domestic market and the commodity has been commercially imported (Minot et al, 2015). Further, the PRA study result shows that wheat and maize are the major focus crop that the food insecure moisture stressed areas grow. Due to lack of appropriate technology it was observed that continuous production failure is usual business. Observing is bottle neck, increasing the food insecure HHs access to appropriate wheat technology that respond to moisture shortage and disease will add value to the goal

\footnotetext{
${ }^{57}$ Non beneficiaries of productive safety net

${ }^{58}$ Productive safety net beneficiaries
} 
of reducing months of food shortage through improving production and productivity. Therefore, this activity was initiated with the objective of demonstration and promotion of wheat technologies that are recommended and mostly preferred by farmers in the intervention area.

\section{Objective}

- To demonstrate improved bread wheat and evaluate productivity and profitability in the study area

- To facilitate the sustained availability and utilization of improved bread wheat in the area

- To improve the improved wheat system innovation through enhancing farmers' role in wheat production.

\section{Research Methodology}

\subsection{Description of the study area}

Sire, Dodota and Ziway Dugda are the three-district found in Arsi zone. All the three districts are known for moisture stress and potential for wheat production. Similarly, Negelle Arsi, is a district found in west arsi zone, on the way of Shashemene to Addis Ababa. All the four district is known to be found in the rift valley.

\subsection{Materials used}

Drought tolerant wheat variety is identified. Accordingly, Ogolcho, and kingbird was used for the purpose of demonstration. All Agronomic input was used as per the recommended package. Among inputs used, NPS $\mathrm{B}_{\mathrm{B}}$ UREA, herbicide and fungicide was applied as per the recommendation.

\subsection{Site Selection and Research Design}

The study was conducted in Negelle Arsi, Sire, Ziway Dugda, and Dodota districts. One intervention kebele from each district with total of 4 (four) kebele was addressed. Within each kebele A total of 12 farmers were used as demonstration hosting farmer. Among the twelve host farmers in each kebele $30 \%$ (four) female farmers are intentionally considered. The demonstration was conducted as a support project to food insecure household, so that among the total targeted farmers $80 \%$ were PSNP-4 (productive safety-net program- 4 beneficiary) farmers at each kebele whereas, $20 \%$ were non-beneficiary. For the demonstration purpose Plot size of 0.25 ha of land was used for single variety. A total of 0.75 ha of land was used to lay the two-variety side by side along with local check. Fertilizer at recommended rate of $100 \mathrm{~kg} / \mathrm{ha}$ NPS at planting time and $100 \mathrm{~kg} / \mathrm{ha}$ UREA after 15 days of planting as side dressing was used. All agronomic and yield data was received from an area of $2 \mathrm{~m} * 2 \mathrm{~m}$ with quadrant for the purpose of estimation. Frequent monitoring and follow up was done during the experimentation. All the collected data is analyzed through Excel, and descriptive statistics.

\section{Result and discussion}

\subsection{Adaptability and General characteristics of Varieties used in demonstration}

As depicted in the table generally the two varieties used for the demonstration purpose was developed for moisture stress area and is with in the agroecological range of the research and demonstration sites. It matures from 90-102 days, require of rain of 400-800 $\mathrm{mm}$. Adaptable to varied altitude which includes the elevation range of the demonstration sites.

Table:1 general characteristics of wheat variety under demonstration

\begin{tabular}{llllc}
\hline Variety name & Days to maturity & Rainfall $(\mathbf{m m})$ & Altitude $\mathbf{( m . a . s l )}$ & Potential yield in qt. \\
\hline Ogolcho & 102 & $400-500$ & $1600-2100$ & $33-50$ \\
Kingbird & 90 & $500-800$ & $1500-2200$ & $33-52$ \\
\hline
\end{tabular}

Ogolcho and King bird varieties used for the demonstration purpose were released for moisture stress areas and thus, fits to the agroecological range of the research and demonstration sites.

Days to maturity for Ogolcho and King bird are 90 and 102 days respectively. Yielding potentials of the varieties at research station ranges from $33-50$ quintals and $33-52$ quintal per hectare for Ogolcho and King bird respectively. The average yield of Ogolcho at demonstration site was 32.8 quintals per ha while that of Kingbird was 33.8 quintal per ha. Both varieties were found superior to the local check. In Sire, Ziway Dugda and Dodota woredas, yield performance of both varieties under women PSNP farmers were higher than men PSNP farmers. Conversely, the result was the other way around for Non PSNP farmers in that order. The findings under Nagelle Arsi woreda however showed that men's field yield performance was higher than women's under PSNP farmers while it was higher for women under Non PSNP farmers (table 2). 
Table 2: Wheat demonstration yield data result by gender and food security status

\begin{tabular}{|c|c|c|c|c|c|c|c|c|}
\hline \multirow{3}{*}{ Treatment } & \multicolumn{4}{|c|}{ Sire district } & \multicolumn{4}{|c|}{ Dodota District } \\
\hline & \multicolumn{2}{|c|}{ PSNP } & \multicolumn{2}{|c|}{ NPSNP } & \multicolumn{2}{|c|}{ PSNP } & \multicolumn{2}{|c|}{ NPSNP } \\
\hline & women & Men & women & Men & women & Men & women & Men \\
\hline Ogolcho & 51.25 & $34 . .5$ & 20.4 & 52 & 34 & 33.3 & 20.4 & 36 \\
\hline Kingbird & 48.75 & 36.5 & 24 & 44 & 26 & 24.0 & 24 & 30 \\
\hline \multirow[t]{2}{*}{ Local } & 29 & 21.5 & 16 & 32 & 20 & 14.7 & 16 & 16 \\
\hline & \multicolumn{4}{|c|}{ Ziway Dugda district } & \multicolumn{4}{|c|}{ N/Arsi District } \\
\hline \multirow[t]{2}{*}{ Treatment } & \multicolumn{2}{|c|}{ PSNP } & \multicolumn{2}{|c|}{ NPSNP } & \multicolumn{2}{|c|}{ PSNP } & \multicolumn{2}{|c|}{ NPSNP } \\
\hline & women & Men & women & Men & women & Men & women & Men \\
\hline Ogolcho & 43.75 & 20 & 37.5 & 37.5 & 52.5 & 55 & 45 & 37.5 \\
\hline Kingbird & 43.75 & 17.5 & 38.75 & 22.5 & 40 & 50 & 40 & 31.25 \\
\hline Local & 42.5 & 20 & 35 & 27.5 & 25 & 37.5 & 35 & 26.15 \\
\hline \multicolumn{9}{|c|}{ Average yield for Ogolcho, King bird, and local were $32.8,33.8$, and 25.8 Quintals per hectare respectively } \\
\hline \multicolumn{9}{|c|}{$\begin{array}{l}\text { Compared to the national and regional CSA (2018) average yield recorded for wheat ( } 27 \text { and } 30 \text { quintals per } \\
\text { hectare respectively), the average result obtained under the demonstration had shown the yield advantage of } 22 \% \\
\text { and } 12 \% \text { respectively. }\end{array}$} \\
\hline \multirow{2}{*}{\multicolumn{9}{|c|}{$\begin{array}{l}\text { 3.2. Farmers preferences } \\
\text { Farmers preference evaluation was carried out during frequent field supervision, field day, and during } \\
\text { acceptability scoring by host farmers indicated their interest and preference towards Ogolcho, regardless of the } \\
\text { yield advantage of Kingbird. The reason for this was the variety has good seed weight, larger number of seeds } \\
\text { per spike, and highly preferred seed size and color. In addition, the less preferability of Kingbird regardless of its } \\
\text { early maturing nature, its relative shattering property, and very tiny seed size made it less preferable. } \\
\text { Table 3: Farmers Preference (Acceptability score) conducted under selected woredas }\end{array}$}} \\
\hline & & & & & & & & \\
\hline \multicolumn{3}{|c|}{ Treatment } & \multicolumn{3}{|c|}{ Sire District $(\mathrm{n}=5)$} & \multicolumn{3}{|c|}{ N/Arsi District $(n=5)$} \\
\hline Ogolcho & & & 00 & & & 93.3 & & \\
\hline King Bird & & & 6.7 & & & 73.3 & & \\
\hline Local & & & 3.3 & & & 33.3 & & \\
\hline
\end{tabular}

\subsection{Stakeholders feedback}

In addition to the farmers preference analysis, stakeholders feed backs were collected on the two improved wheat varieties and variety used as a local control. The stakeholders feedback showed that coupled with adequate supply of seed and necessary input at the right time, the promotion of both improved wheat varieties would result in better yield and contributes to household food security.

Table 4: Stakeholders feedback

\begin{tabular}{llll}
\hline Key stakeholder & $\begin{array}{c}\text { Stakeholders } \\
\text { feedback }\end{array}$ & Issue that need further improvement \\
\hline Farmers & $\begin{array}{l}\text { Promote } \\
\text { scaling up }\end{array}$ & $\begin{array}{l}\text { Early input delivery, either of variety based on the metrological } \\
\text { information, if rain starts on time, we need Ogolcho, when rain onset is } \\
\text { late kingbird is adequate. } \\
\text { The adequate amount use of input is very important for yield, it is } \\
\text { important if there is a means to access credit so that we use package. }\end{array}$ \\
& & $\begin{array}{l}\text { Wheat row planting requires high number of labors, which is not } \\
\text { available at planting time, any technology that reduce labor } \\
\text { requirement }\end{array}$ \\
\hline Extension (WoA) & Promote & $\begin{array}{l}\text { Clustering, is very important, we must work on adequate and timely } \\
\text { input delivery }\end{array}$ \\
\hline PSNP Office & Promote & Clustering based outreach in all area is appropriate method to follow \\
\hline
\end{tabular}

The project and the extension part should think from now on effective use meteorological forecast for appropriate seed selection for the area. The other way, for ease of management supervision, market facility and impact clustered production should be focused so that better capacity will be obtained. Community based marketing systems should also be thought once people are starting to produce more. The most important issue in wheat production is, row planting of wheat with local material is a labor-intensive, which is critically short at main planting season and harvesting cost with combiner harvester for which brokers make cost of harvesting per quintal very expensive. Better can be gained if research and development organizations work on how to solve and improve pre- and post-harvest aspects through intermediate pre harvest and post-harvest technology demonstration and promotion. 


\subsection{Economic analysis}

Profitability analysis using partial budget analysis was undertaken. Costs captured as varying cost (variable costs) include cost of land preparation, weeding, seed, fertilizer, chemical, and cost of harvesting, while revenue were computed using quantity of produce and market price. Accordingly, the improved varieties in all locations demonstrated superior to the local check differently (Table 5).

Table 5: Production and profitability analysis

\begin{tabular}{cccccccc}
\hline \multirow{2}{*}{ District } & Treatment & $\begin{array}{c}\text { Revenue } \\
\text { (ETB) }\end{array}$ & $\begin{array}{c}\text { TVC } \\
\text { (ETB) }\end{array}$ & $\begin{array}{c}\text { Profit } \\
\text { (ETB) }\end{array}$ & $\begin{array}{c}\text { Revenue } \\
\text { (ETB) }\end{array}$ & $\begin{array}{c}\text { TVC } \\
\text { (ETB) }\end{array}$ & $\begin{array}{c}\text { Profit } \\
\text { (ETB) }\end{array}$ \\
\hline \multirow{2}{*}{ Sire } & Ogolcho & 45,417 & 18,511 & 26,906 & 45,250 & 18,458 & 26,792 \\
& King bird & 48,521 & 18,977 & 29,544 & 42,500 & 18,509 & 23,991 \\
& Local & 28,038 & 18,005 & 10,033 & 30,000 & 12,920 & 17,080 \\
\hline \multirow{2}{*}{ Dodota } & Ogolcho & 45,360 & 16,760 & 28,600 & 48,600 & 17,000 & 31,600 \\
& King bird & 33,480 & 16,129 & 17,351 & 40,500 & 16,649 & 23,851 \\
& Local & 22,680 & 10,261 & 12,419 & 21,600 & 9,360 & 12,240 \\
\hline Ziway & Ogolcho & 50,167 & 17,157 & 33,010 & 52,500 & 17,217 & 35,283 \\
Dugda & King bird & 49,000 & 17,322 & 31,678 & 46,667 & 17,049 & 29,618 \\
& Local & 49,000 & 12,790 & 36,210 & 45,500 & 18,293 & 27,207 \\
\hline N/Arsi & Ogolcho & 75,250 & 19,438 & 55,813 & 56,000 & 18,267 & 37,733 \\
& King bird & 63,000 & 18,899 & 44,101 & 47,833 & 17,991 & 29,843 \\
& Local & 43,750 & 17,423 & 26,328 & 40,740 & 16,079 & 24,661 \\
\hline Average & Ogolcho & $54,048.50$ & $17,966.50$ & $36,082.25$ & $50,587.50$ & $17,735.50$ & 32,852 \\
& King bird & $48,500.25$ & $17,831.75$ & $30,668.50$ & $44,375.00$ & $17,549.50$ & $26,825.75$ \\
& Local & $35,867.00$ & $14,619.75$ & $21,247.50$ & $34,460.00$ & $14,163.00$ & 20,297 \\
\hline
\end{tabular}

The highest yield and profit were obtained at Negele Arsi for both PSNP and NPSNP beneficiaries for both Ogolcho and king bird. Overall, as indicated in the table above, the use of improved production packages and improved variety in the drought prone area will result in better production and profit thereby contributing to household food and income security.

\section{Conclusion and Recommendation}

Improving production and productivity of wheat technology is a matter of delivering appropriate technology at appropriate time. It has been learnt that careful selection of technology package along with early preparation is necessary for the areas with rainfall uncertainty.

Kingbird is the most productive variety in the area, followed by Ogolcho. Irrespective of its productivity farmers preferred ogolcho. This is mainly due to several related factors, among which, ogolcho has good taste quality, seed size and better seed color. Farmers also put a pre-condition on the decision of extensive use of either Ogolcho or Kingbird for production. Based on the discussion made with farmers the use of either of the variety based on the response farming to agrometeorological forecast is necessary. When there is a forecast of adequate and enough moisture promoting ogolcho will result in better yield and farmers satisfaction and when there is no adequate or enough moisture targeting kingbird results in better result of intervention. The Wereda and project team should work on providing and advising farmers with adequate meteorological information and delivery of appropriate technology.

The use of package of technology would result in better yield and profitability. Improving farmers access to improved technology and extension advisory service would better result enhanced knowledge, skill and attitude of poor and non-poor men and women farmers, thereby contribute to food self-sufficiency.

Attention should be given to Early input delivery specially improved variety, based on the meteorological information. For instance, for late start of rainfall kingbird better and when rainfall is on time Ogolcho is appropriate.

Extensive awareness creation and promotion on the use of adequate amount of input (seed and fertilizer) is very important for yield. further, enhanced used of the recommended quantity of input requires facilitating input credit service. Wheat row planting requires high number of labors, which is at short during planting time, mechanized row planter farm implement would be a solution with due attention to its careful diagnosis of unintended effect on gender role to reduce labor required.

\section{Reference}

Bezabeh, E. Haregewoin,T. Hailegiorgis, D. Daniel F. and Belay B.2015. Change and growth rate analysis in area, yield and production of wheat in Ethiopia. Research Journal of Agriculture and Environmental Management. Vol. 4(4). Available online at http://www.apexjournal.org.

Tefera, A. 2013. GAIN (Global Agricultural Information Network): Ethiopia Grain and Feed Annual Report. 
Report number ET-1301.

Tefera, A. 2012. GAIN (Global Agricultural Information Network): Ethiopia Grain and Feed Annual Report. Report number ET-1201.

Minot, N., Warner, J. Lemma, S. Kasa, L. Gashaw, A. Rashid S. 2015. The Wheat Supply Chain in Ethiopia: Patterns, trends, and policy options, IFPRI, Washington DC.

Nigussie A., Kedir A., Adisu A., Belay G., Gebrie D. and Desalegn K. (2015). Bread Wheat Production in Small Scale Irrigation Users Agro-Pastoral Households in Ethiopia: Case of Afar and Oromia Regional State. Journal of Development and Agricultural Economics, Vol. 7(4), pp. 123-130. 